Preface

\title{
Advances in Mucopolysaccharidoses
}

\author{
Susanne G. Kircher, MD, PhD, MBA ${ }^{1}$ Adriana M. Montaño, PhD ${ }^{2,3}$ Christina Lampe, MD ${ }^{4,5}$
}

${ }^{1}$ Center of Pathobiochemistry and Genetics, Medical University of

Vienna, Vienna, Austria

${ }^{2}$ Department of Pediatrics, Doisy Research Center, School of Medicine, Saint Louis University, St. Louis, Missouri, United States

${ }^{3}$ Department of Biochemistry and Molecular Biology, School of

Medicine, Saint Louis University, St. Louis, Missouri, United States

${ }^{4}$ Center for Rare Diseases, Klinik für Kinder und Jugendliche, HSK,

Dr. Horst Schmidt Kliniken GmbH, Wiesbaden, Germany

5 Klinikum der Landeshauptstadt Wiesbaden und der HELIOS Kliniken

Gruppe, Wiesbaden, Germany

J Child Sci 2018;8:e113-e115.

The story of the mucopolysaccharidoses (MPS) began more than a hundred years ago, with pivotal reports describing a new disease. In 1917, Scottish physician Charles Hunter described "a rare disease in two brothers" with distinct face and physical abnormalities such as hearing deficits, inguinal hernias, claw-like hand position, protruding abdomen, and intellectual impairment. Soon after (1919), Austrian pediatrician Professor Meinhard von Pfaundler ${ }^{1}$ and his German colleague, Dr. Gertrud Hurler, ${ }^{2}$ reported a special form of skeletal dysostosis in childhood. They observed the coincidence of femoral head dysplasia, hip changes, malformed vertebral bodies, shortening and thickening of meta- and epiphyses of long bones, macrocephaly and premature synostosis of coronal suture, and wide sella turcica. The published multiple skeletal changes in two unrelated children, later defined as "dysostosis multiplex," defined the distinct skeletal abnormalities observed in all patients with mucopolysaccharide storage disorders. Patients with similar skeletal changes were described by Brailsford and Morquio in 1929, prompting one type of MPS to be named Brailsford-Morquio or Morquio syndrome.

In the middle of the last century, scientists and physicians focused on the biochemical and histological findings in similar patients, such as storage in white blood cells, tissues, and organs. ${ }^{3,4}$ Special dyes for glycogen and sugars showed the origin in sugar-like components called "mucopoly-saccharides," which also were found in higher amounts in patients' urine (Dorfman and Lorincz, 1957/58). From the 1960s on, patients were further differentiated within a new group of diseases named MPS or mucopolysaccharide storage diseases. ${ }^{5}$ Articles offered first descriptions and distinctions between Sanfilippo syndrome (Sanfilippo et al, 1963), Scheie syndrome in adults (Scheie et al, 1962), and Maroteaux-Lamy syndrome (observed by French physicians Maroteaux and Lamy, 1963). ${ }^{6-8}$ All these patients had clinical similarities, but also differences, such as the fact that some conditions occurred only in males (Hunter syndrome).

As often happens in science, a very important finding was made by chance. In 1968/69, Dr. Elizabeth Neufeld and colleagues accidentally co-cultivated fibroblasts from two different patients, and unexpectedly observed the correction of the storage disorder in these cells (Fratantoni et al). ${ }^{9}$ Systematic investigation proved that factors in the cell culture media caused the correction. Many different "correcting factors" were revealed and recognized as proteins, or more precisely enzymes, that degrade "acid glycosaminoglycans." Identifying the enzymes made it possible to reclassify systematically the MPS. Alpha-1-iduronidase was identified as the enzyme deficient in MPS I in children and young patients (Hurler syndrome) but also MPS V in adults (Scheie syndrome). Several enzymes were causing the same clinical picture, making it necessary to create subtypes as in MPS III (Sanfilippo disease) and MPS IV (Morquio disease).

From the moment it was recognized that MPS I (Hurler disease) and MPS V (Scheie disease) result from the same enzyme deficiency, it was clear that mucopolysaccharide storage disorders exhibit a wide range of severity and symptoms. At this time, too, the Hunter and Hurler articles were recognized as observations from two different MPS types: type I or Hurler (earlier described as Pfaundler-
Address for correspondence Susanne G. Kircher, M.D., Ph.D., MBA, Center of Pathobiochemistry and Genetics Medical University of Vienna, Waehringer Strasse 10, 1090 Vienna, Austria (e-mail: susanne. kircher@meduniwien.ac.at).
Issue Theme Advances in Mucopolysaccharidoses; Guest Editors, Susanne G. Kircher, MD, PhD, MBA, Adriana M. Montaño, $\mathrm{PhD}$, and Christina Lampe, MD.

DOI https://doi.org/ 10.1055/s-0038-1667191. ISSN 2474-5871.
Copyright (c) 2018 Georg Thieme Verlag License terms KG Stuttgart · New York 
Hurler syndrome) disease and type II or Hunter disease. In fact, the observation that Hunter's disease only affected males confirmed the autosomal recessive inheritance in all MPS types except MPS II, which shows a X-chromosomal recessive trait.

In 1973, Dr. William Sly and colleagues reported a boy with dysostosis multiplex, hepatosplenomegaly, hernias, unusual facies, and cognitive impairment. This condition is known as MPS VII (Sly syndrome). ${ }^{10}$ Studies of the boy's cells had an important impact on the field. Currently, we know that MPS VII is characterized by a heterogeneous phenotype including non-immune neonatal hydrops fetalis in the most severe form of the disease. Later, Dr. Marvin Natowicz described clinical and biochemical manifestations of hyaluronidase deficiency (MPS IX), including nodular soft-tissue masses around joints, with periodic painful swelling of the masses, flattened nasal bridge, and short stature (Natowicz et al, 1996). ${ }^{11}$

Elizabeth Neufeld's observation about cross-correction of different patients' cells was a milestone and the basis for future therapies. From the 1980s, transplanting bone marrow and later hematopoietic stem cells were thought to be the best options to cure MPS. Donor cells, migrating into different organs, could secrete enzymes to be taken up by cells missing them. Of course, these foreign cells induced immune reactions, and any immune suppression had severe consequences. Morbidity and mortality after such procedures were very high before methods improved. Blood transfusions, plasma infusions, and cell transplantation with low immune reaction such as skin fibroblasts or amniotic cells, all failed to produce enough enzyme protein for clinical improvement.

Progress has been enormous and Chinese hamster ovarian cells, human fibroblasts, and even plant cells now produce enzymes for MPS patients. Modifying glycosylation of enzymes produced in vitro allowed them to reach organs and tissues they previously could not, such as bones and cartilage. Enzymes were supplemented exclusively intravenously, but can now be administered intrathecally or intracerebrally, to reach the brain and nervous system.

Physicians and scientists all over the world were responsible for the enormous gain in knowledge about mucopolysaccharide storage disorders. The probably most recent MPS type was described in 2015 by Kowalewski et al with the MPS type IIIE or Sanfilippo type IIIE. ${ }^{12}$ On one hand, the success was based on intensive international researcher cooperation, but increasing diagnoses worldwide also added to the urgency to develop new therapies. Therapies for these rare and ultra-rare disorders have benefited from new government regulations, and patient advocacy groups supported these efforts by providing information about MPS natural history, taking part in clinical trials and funding research. Continuous information exchange is supported by international symposia organized every second year by national MPS societies around the world.

Patient cooperation and collaboration are very special in the community of MPS patients and their families, but also with all involved in the health-care system. Patients were recognized as individuals with special needs, hopes, and wishes. As one of the first pediatricians to specialize in MPS, Ed Wraith from the UK confirmed, the patient must come first in all the efforts made for MPS diseases. Each of his talks and lectures reflected on the individual human being who should not be overlooked. From the patient's side, the Lavery family from the UK, especially Christine Lavery, started the English MPS society 35 years ago, creating a shining example for groups in many countries. So many people working for MPS and patients should be mentioned, but the guest editors dedicate this special issue about "Advances in Mucopolysaccharidoses" especially to Ed and Christine, who died not long ago in the middle of their active work. We would not have reached the level we have without them. It is no wonder that some of their colleagues and friends have written articles in this issue.

Many articles deal with the challenges of longer survival resulting from existing and new therapies. For instance, orthopedic surgery now offers patients the chance for a worthwhile life. With any operation, however, anesthesia risks increase and shall be overcome. Neuronopathic forms of MPS have long been untreated because survival was restricted to a few years. Longer survival creates the need to treat their clinical problems. Sleep apnea is observed in many types of MPS, with or without impaired development. Treating it enormously improves quality of life. Longer survival also means plans for family life and children; the genetic counseling and experiences of other MPS patients as parents help in weighing these options. Last but not least, we also invited one patient and family to give an insight in their daily life.

We hope this special issue can give new insights into these fascinating diseases, and give readers help and advice to overcome the high challenges of patients suffering these disorders.

\section{References}

1 Hunter C. A rare disease in two brothers. Proc R Soc Med 1917; 10:104-116

2 Hurler G. Über einen Typ multipler Abartungen, vorwiegend am Skelettsystem. Z Kinderheilkd 1920;24:220-234

3 Brailsford JF. Chondro-osteo-dystrophy. Roentgenographic and clinical features of a child with dislocation of vertebrae. Am J Surg 1929; 7:404-410

4 Morquio L. On a form of familial osseous dystrophy (Sur une forme de dystrophie osseuse familiale). Bull Soc Pediatr Paris 1929; 27:145-152

5 Dorfman A, Lorincz AE. Occurrence of urinary acid mucopolysaccharides in the Hurler syndrome. Proc Natl Acad Sci USA 1957;43 (06):443-446

6 Sanfilippo SJ, Podosin R, Langer LO, Good RA. Mental retardation associated with acid mucopolysacchariduria (heparitin sulfate type). J Pediat 1963;63:837-838

7 Scheie HG, Hambrick GW Jr, Barness LA. A newly recognized forme fruste of Hurler's disease (gargoylism). Am J Ophthalmol 1962;53:753-769

8 Maroteaux P, Leveque B, Marie J, Lamy M. A new dysostosis with urinary elimination of chondroitin sulfate B [Article in French]. Presse Med 1963;71:1849-1852 
9 Fratantoni JC, Hall CW, Neufeld EF. Hurler and Hunter syndromes: mutual correction of the defect in cultured fibroblasts. Science 1968;162(3853):570-572

10 Sly WS, Quinton BA, McAlister WH, Rimoin DL. Beta glucuronidase deficiency: report of clinical, radiologic, and biochemical features of a new mucopolysaccharidosis. J Pediatr 1973;82(02):249-257

11 Natowicz MR, Short MP, Wang Y, Dickersin GR, Gebhardt MC, Rosenthal DI, Sims KB, Rosenberg AE. Clinical and biochemical manifestations of hyaluronidase deficiency. N Engl J Med 1996; 335(04):1029-1033

12 Kowalewski B, Heimann P, Ortkras T, Lüllmann-Rauch R, Sawada T, Walkley SU, Dierks T, Damme M. Ataxia ist he major neuropathological finding in arylsulfatase G-deficient mice: similarities and dissimilarities to Sanfilippo disease (mucopolysaccharidosis type III). Hum Mol Genet 2015;24(07): 1856-1868 